\title{
Phase-shifted Bragg grating inscription in PMMA microstructured POF using 248 nm UV radiation
}

\author{
Pereira, L.; Pospori, A.; Antunes, Paulo; Domingues, Maria Fatima; Marques, S.; Bang, Ole; Webb, David \\ J.; Marques, Carlos A.F.
}

Published in:

Journal of Lightwave Technology

Link to article, DOI:

10.1109/JLT.2017.2771436

Publication date:

2017

Document Version

Peer reviewed version

Link back to DTU Orbit

Citation $(A P A)$ :

Pereira, L., Pospori, A., Antunes, P., Domingues, M. F., Marques, S., Bang, O., Webb, D. J., \& Marques, C. A. F. (2017). Phase-shifted Bragg grating inscription in PMMA microstructured POF using $248 \mathrm{~nm}$ UV radiation. Journal of Lightwave Technology, 35(23), 5176-5184. https://doi.org/10.1109/JLT.2017.2771436

\section{General rights}

Copyright and moral rights for the publications made accessible in the public portal are retained by the authors and/or other copyright owners and it is a condition of accessing publications that users recognise and abide by the legal requirements associated with these rights.

- Users may download and print one copy of any publication from the public portal for the purpose of private study or research.

- You may not further distribute the material or use it for any profit-making activity or commercial gain

- You may freely distribute the URL identifying the publication in the public portal 


\title{
Phase-Shifted Bragg Grating Inscription in PMMA Microstructured POF Using 248-nm UV Radiation
}

\author{
Luis M. Pereira, A. Pospori, Paulo Antunes, Maria Fatima Domingues, S. Marques, Ole Bang, \\ David J. Webb, Member, IEEE, and Carlos A. F. Marques
}

\begin{abstract}
In this work, we experimentally validate and characterize the first phase-shifted polymer optical fiber Bragg gratings (PS-POFBGs) produced using a single pulse from a 248-nm krypton fluoride laser. A single-mode poly (methyl methacrylate) optical fiber with a core doped with benzyl dimethyl ketal for photosensitivity improvement was used. A uniform phase mask customized for 850-nm grating inscription was used to inscribe these Bragg structures. The phase shift defect was created directly during the grating inscription process by placing a narrow blocking aperture in the center of the UV beam. The produced high-quality Bragg grating structures, presenting a double dips, reject $16.3 \mathrm{~dB}(97.6 \%$ reflectivity) and $13.2 \mathrm{~dB}(\mathbf{9 5 . 2 \%}$ reflectivity) of the transmitted power, being therefore appropriate for sensing or other photonic applications. Its transmission spectrum possesses two sharp transmission notches, allowing a significant increase in measurement resolution compared to direct interrogation of a single grating. The reflection and transmission spectra when multiple phase shifts are introduced in the fiber Bragg grating structure are also shown. The PS-POFBG's strain, temperature, pressure, and humidity characteristics have been experimentally analyzed in detail to assess their potential usage as sensors.
\end{abstract}

Index Terms-Fiber Bragg gratings, notch filter, optical filtering, polymer optical fiber sensors, ultrasonic detection.

\section{INTRODUCTION}

$\mathbf{P}$ HASE-SHIFTED fibe Bragg gratings (PS-FBGs) in silica fiber have been demonstrated during the last decade as

Manuscript received August 14, 2017; revised November 2, 2017; accepted November 4, 2017. Date of publication November 7, 2017; date of current version November 20, 2017. This work was supported by Fundação para a Ciência e Tecnologia (FCT)/MEC through national funds and when applicable co-funded by FEDER - PT2020 partnership agreement under Project UID/EEA/50008/2013. The work of C. A. F. Marques and M. F. Domingues was also supported by FCT through the fellowships SFRH/BPD/109458/2015 and SFRH/BPD/101372/2014, respectively. (Corresponding author: Carlos A. F. Marques.)

L. Pereira, P. Antunes, M. F. Domingues, and C. A. F. Marques are with the Instituto de Telecomunicações, and Physics Department \& I3N, Universidade de Aveiro, 3810-193, Aveiro, Portugal (e-mail:1mpereira@ua.pt; pantunes@ua.pt; fatima.domingues@ua.pt; cmarques@av.it.pt).

A. Pospori and D. J. Webb are with the Aston Institute of Photonic Technologies, Aston University, Birmingham B4 7ET, U.K. (e-mail: a.posporis@aston. ac.uk; d.j.webb@aston.ac.uk).

S. Marques is with the Wrocław University of Science and Technology, 50-370 Wrocław, Poland (e-mail: s.marques@ua.pt).

O. Bang is with the DTU Fotonik, Department of Photonics Engineering, Technical University of Denmark, DK-2800 Kgs. Lyngby, Denmark (e-mail: oban@fotonik.dtu.dk).

Color versions of one or more of the f gures in this paper are available online at $\mathrm{http}: / /$ ieeexplore.ieee.org.

Digital Object Identifie 10.1109/JLT.2017.2771436 attractive narrow-band filter for a variety of applications in photonics.

Recently published papers report PS-FBG applications also in the microwave photonics field for example as tunable microwave photonic filters which opens new perspectives for these devices [1]-[3]. Tailoring the transmission FBG spectrum to obtain very narrow stop bands can be achieved through the introduction of a phase shift across the grating. The properties of phase shifted gratings were firs demonstrated in periodic structures using semiconductor materials [4]. Consequently, different techniques were developed to produce phase-shifts in optical fiber [5]-[8].

In many applications, such as non-destructive testing, structural health monitoring, and biomedical imaging [9], [10], ultrasonic optical sensors have been proposed as an alternative to traditional piezoelectric sensors, due to several advantages, such as their small size, light weight, and immunity to electromagnetic interference. In particular, optical fibe ultrasonic sensors based on FBGs have additional advantages, including in-line fibe structure, ease of multiplexing, and single-ended operation that make them attractive in many sensing applications [11], [12]. In these FBG systems, ultrasonic detection is achieved by identifying the ultrasound-induced shift of the FBG reflectio spectrum. A concern for an FBG ultrasonic sensor system in practical applications is the limitation of the signalto-noise ratio. The signal strength, which is proportional to the slope of the reflectio spectrum, can be increased with the use of phase-shifted fibe Bragg gratings as the sensing element [13]-[15]. This device features a phase shift in the middle of an otherwise periodic grating structure, which leads to a strong optical resonance and a narrow notch in the reflectio spectrum with much larger spectral slope than a uniform FBG of the same length.

As the fabrication technology of FBGs in silica fiber is already well established, PS-FBGs inscribed in such fiber were studied for numerous practical applications. In recent years, the polymer optical fibe Bragg gratings (POFBGs) fabrication technology has been intensively established using uniform FBGs [16]-[19], tilted FBGs [20], chirped FBGs [21], and FBGbased Fabry-Perot interferometers [22]. Specifi material properties, such as low Young's modulus (about $3 \mathrm{GPa}$ compared to $72 \mathrm{GPa}$ for silica), a very large breaking strain, as well as biological compatibility, opens a variety of new applications unattainable for silica fibers In the published literature, one can 
fin studies reporting on applications of single FBGs in POFs as sensors of strain [23], acoustic waves [24], temperature [23], [25], humidity [25], accelerometer [26] or liquid level [27], [28]. In the last years, there has been an increase in the research of POF technology for biomedical applications [29]-[34]. In 2015, Broadway et al showed the POF potential for endoscopic operation [35]. Recently, the same group presented for the firs time opto-acoustic measurements using a microstructured polymer optical fibe (mPOF) FBG with a $130 \mu \mathrm{m}$ diameter fibe and presented the lateral directivity pattern of an ultrasound sensor over a frequency range of $1-50 \mathrm{MHz}$ [36], [37]. These works showed that the acoustic sensitivity for POF is 13 times higher than for silica optical fibe. Furthermore, 3 times more sensitivity can be achieved using mPOF than with the other POFs and a potential transition from uniform POFBGs to Fabry-Perot cavities or phase-shifted POFBGs (PS-POFBGs) can expand the potential that POF has to offer in this fiel [36], [37]. The goal with that is to deliver a narrower spectral shape, which can potentially be used to achieve higher sensitivities. Until now, the literature only provided a single report on a PS-FBG in POF, which was used at $\mathrm{THz}$ frequencies (grating period $=250 \mu \mathrm{m}$ ) via a point-by-point FBG fabrication method using a $248 \mathrm{~nm}$ $\mathrm{KrF}$ excimer laser [38]. However, the point-by-point approach is time-consuming and much more difficul to implement for gratings in the $850 \mathrm{~nm}$ or $1550 \mathrm{~nm}$ spectral regions. There is also another work published in 2006 [39] where a weak PS-FBG in POF in the $1550 \mathrm{~nm}$ region is shown, however with lack of sharpness in the central reflectio notch and with inscription times in the order of tens of minutes.

For the firs time, we report high-quality PS-POFBGs inscribed with a single krypton fluorid $(\mathrm{KrF})$ laser pulse for operation in the $850 \mathrm{~nm}$ region. A single-mode poly (methyl methacrylate) (PMMA) optical fibe doped with benzyl dimethyl ketal (BDK) for photosensitivity enhancement in the core region was used. A $10 \mathrm{~mm}$ long uniform phase mask, customized for a $248 \mathrm{~nm}$ UV laser, was used to inscribe FBGs in the $850 \mathrm{~nm}$ spectral region. The phase shift defect was created directly during the grating inscription process by placing a narrow blocking aperture in the center of the UV beam. The phase shift occurs because, where the UV beam is blocked, the mean fibe index is less than in the rest of the grating. Only a single $15 \mathrm{~ns}$ laser pulse with an energy of $6.3 \mathrm{~mJ}$ is sufficien to produce a refractive index change of $0.69 \times 10^{-4}$ in the fibe core. The produced high-quality Bragg grating structures reject $16.3 \mathrm{~dB}$ transmitted power for the strong dip, providing $97.6 \%$ reflec tivity, and $13.2 \mathrm{~dB}$ transmitted power for the other dip, which is appropriate for most sensing proposes. Furthermore, the reflecte and transmission spectra when multiple phase shifts are introduced in the FBG structure are shown. The PS-POFBG's temperature, strain, humidity and pressure characteristics are also experimentally studied. These PS-POFBGs can be useful optical devices not only for optical sensing but also for different photonic applications, such as a narrowband transmission fil ters for a variety of applications at telecom wavelengths. Their use is viable at telecom wavelength since these structures can be fabricated in $1550 \mathrm{~nm}$ spectral region using short pieces of fiber due to high fibe losses in this spectral region.

\section{THEORY OF PS-FBG STRUCTURES}

A phase-shift in the Bragg structure (longitudinal axis z) leads to a deviation in the reflectio coefficient $r(z)$ and transmission coefficient $t(z)$, given by [40]:

$$
\begin{aligned}
& t(z)=t_{0} e^{-j \phi N_{T}(z)} \\
& \text { and } \\
& r(z)=r_{0} e^{-j \phi N_{R}(z)}
\end{aligned}
$$

where, $\phi$ is the phase shift, $N_{T}(z)$ and $N_{R}(z)$ represent the effective number of passes experienced by transmitted and reflecte light in the defect region (the effective phase shift), respectively [40]. Insertion of complex phase shifts has been suggested in different perspectives, and a detailed analysis based on Feynman paths has been well applied to a Fabry-Perot cavity [41]. The introduction of phase-shifts in different positions will affect the different wavelengths in different degrees [40]. Inserting random phase shifts, the longitudinal dependence is averaged and all the wavelengths will be affected. This means that the PS-FBGs can be considered as a particular case of the FabryPerot cavities based on Bragg gratings. The physical mechanism of a PS-FBG can be well understood in analogy with the Fabry-Perot resonators [42]. However, a PS-FBG is not a simple Fabry-Perot cavity, since the reflection are distributed along the fibe length and the reflect vities depend on wavelength.

PS-FBGs were obtained by introducing a phase shift in the refractive index modulation. This phase shift in the middle of the grating structure produces an optical resonance in transmission (that transmits a very narrow linewidth), and a very narrow notch in the reflecte spectrum. The center wavelength of the notch depends on the magnitude of the phase shift (between 0 and $2 \pi$ ) and on its location along the grating [43]. In this context, by introducing a phase shift in the middle of the grating, the result will be the formation of two identical Bragg gratings, separated by a cavity with a length of $L_{c}$. This structure is similar to the Fabry-Perot resonator [42]. The reflection from the firs FBG will be out of phase with the reflection from the second FBG, making interference occur due to the overlap of the light rays reflecte by the two FBGs. The phase shift between the rays reflecte by the two Bragg gratings separated by the cavity $L_{c}$ can be estimated by [42]:

$$
\phi_{\mathrm{FP}}=\frac{2 \pi}{\lambda_{B}} n_{\text {eff }} 2 L_{c}
$$

were, $\lambda_{B}$ is the Bragg wavelength, $n_{\text {eff }}$ the effective refractive index and $L_{c}$ the length of the introduced cavity. Due to the conservation of energy and momentum, the light will be transmitted at this wavelength, opening a narrow gap in the transmission spectrum, within the Bragg grating stop band.

\section{EXPERIMENTAL SETUP AND INSCRIPTION}

A 3-ring microstructured single-mode PMMA POF was used for the PS-POFBG fabrication. Its core and outer diameters are $\sim 8 \mu \mathrm{m}$ and $\sim 130 \mu \mathrm{m}$, respectively. The core of the optical fibe is doped with BDK since this photoinitiator enhances the photosensitivity in PMMA [44]. A detailed information about fibe fabrication is found in [45]. A cross-section image of the POF 
(a)
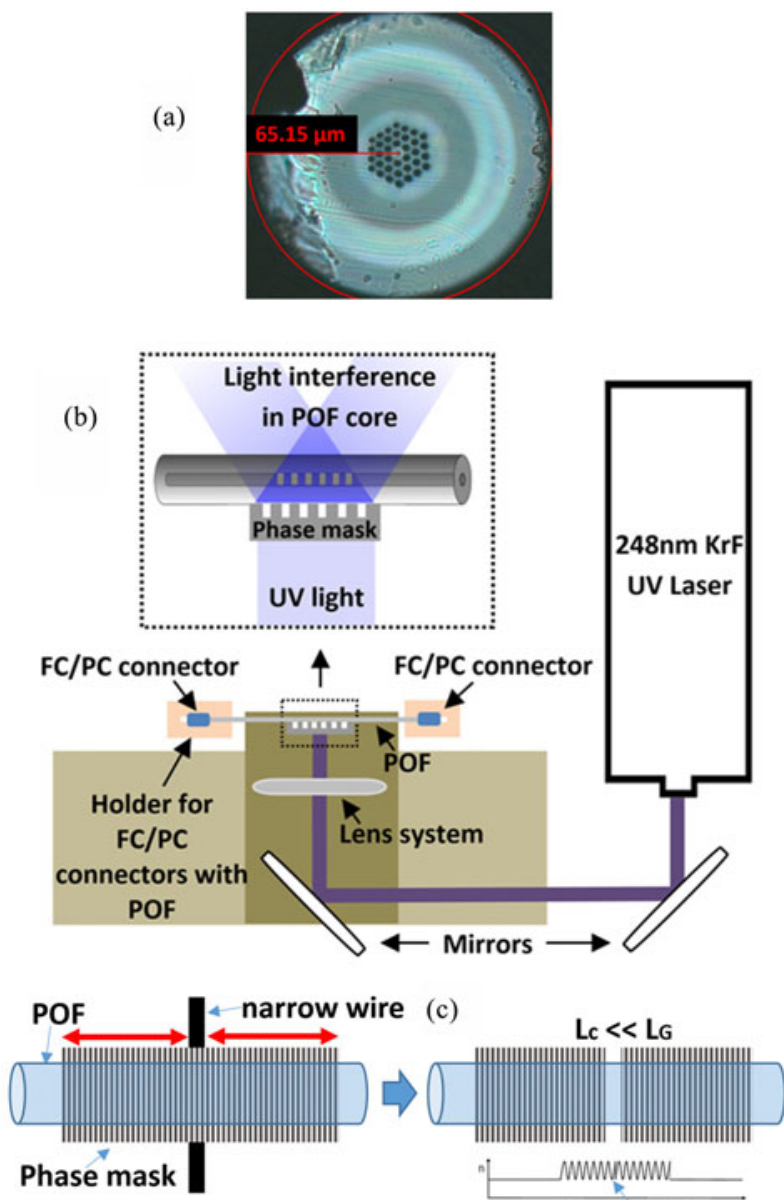

Phase shift

Fig. 1. (a) A cross-sectional image of the mPOF into the ferrule. (b) Setup implemented for the PS-POFBG inscription in a PMMA mPOF by employing the phase mask technique. (c) A schematic configuratio of the PS-POFBG fabricated by inscribing a Bragg structure with a narrow metal wire positioned in the center of the UV beam.

used in this work is shown in Fig. 1(a). The quality of fibr surface is relatively poor because the POF was cleaved by hand due to the non-commercially available POF cleavers. The inscription of such POFBGs have been already reported in this customized fibe using different UV laser systems (a $325 \mathrm{~nm} \mathrm{HeCd}$ and $248 \mathrm{~nm} \mathrm{KrF}$ laser) where the firs needs around 13 minutes of inscription time [45] and the last one employs just one UV pulse [46]. Such a dopant, when irradiated with UV light, acts as a photo-initiator and generates a photo-polymerization process in the core [45] and leads to a positive and strong index change. The BDK absorption coefficien presents much higher values for wavelengths shorter than $325 \mathrm{~nm}$, as shown in [47], and shorter laser inscription wavelengths, such as $248 \mathrm{~nm}$, enhanced its effects [46] using just one pulse. However, it shall be noted that POFBGs were achieved in 7 minutes using $325 \mathrm{~nm} \mathrm{HeCd}$ laser using an undoped fibe [48].

Prior to the gratings fabrication, up to $35 \mathrm{~cm}$ long POF pieces were cleaved using a hot-blade at $70{ }^{\circ} \mathrm{C}$ (this temperature is optimum for PMMA POFs, see [49]) and attached to demountable FC/PC connectors in order to simplify the interrogation of the POFBG. The average loss per connector is less than
$1 \mathrm{~dB}$, which is a considerable improvement compared to previously reported values $(8.45 \mathrm{~dB})$ [50]. All fibe pieces were pre-annealed with the same procedure used in [51], where the fibe was placed for 15 minutes in a vessel fille with heated tap water $\left(60 \pm 1{ }^{\circ} \mathrm{C}\right)$ to remove any residual stresses generated during the drawing process. Several PS-POFBG inscriptions were carried out to guarantee the repeatability of these Bragg structures in POF. A KrF excimer laser system (Coherent Bragg Star Industrial-LN), emitting at $248 \mathrm{~nm}$ wavelength was used. A single $15 \mathrm{~ns}$ laser pulse with a pulse energy of $6.3 \mathrm{~mJ}$ was found to be sufficien for POFBG inscription in a pre-annealed POF. The laser beam profil is a rectangular Tophat function with dimensions $6.0 \times 1.5 \mathrm{~mm}^{2}$ and divergence $2 \times 1 \mathrm{mrad}^{2}$. The laser beam is focused in the fibe core using a plano-convex cylindrical lens (Newport CSX200AR.10) with efective focal length of $200 \mathrm{~mm}$. The effective spot size of the beam on the fibe surface is $20.0 \mathrm{~mm}$ in width and $32.4 \mu \mathrm{m}$ in height. For the PS-POFBG inscription, we used a uniform phase mask technique as displayed in Fig. 1(b). A $10 \mathrm{~mm}$ long phase mask with a period of $\Lambda_{P M}=567.8 \mathrm{~nm}$ was used, which can fabricate FBGs with a wavelength near $\lambda_{B} \approx 844 \mathrm{~nm}$, showing that at such wavelength region the PMMA refractive index is $n=1.486\left(\lambda_{B}=n \Lambda_{P M}\right)$. The phase shift defect was created directly during the grating inscription process by placing a narrow blocking aperture (a metal wire with $40 \mu \mathrm{m}$ diameter) on the phase mask in the center of the UV beam, as schematically illustrated in Fig. 1(c). It resulted in the inscription of two FBGs separated by a very small gap in a single fabrication process, producing a phase shift on the structure. To interrogate the transmission and reflectio spectrum of the grating we used a super luminescent diode (emitting at $843.8 \mathrm{~nm}$ with a spectral bandwidth of $47 \mathrm{~nm}$ ) and an optical spectrum analyzer. A 50/50 optical coupler was used for the reflectio spectrum.

Fig. 2(a) gives the transmission and reflectio spectra of the inscribed PS-FBG after just one UV pulse. Two main dips in the transmission spectrum can be seen, which verifie the successful inscription of the PS-POFBG. The transmission losses of the 1st and 2nd dips are about $-16.25 \mathrm{~dB}$ and $-13.17 \mathrm{~dB}$, and the central wavelengths are $844.126 \mathrm{~nm}$ and $844.187 \mathrm{~nm}$, respectively. The channel spacing between the dips is about $61 \mathrm{pm}$, and the transmission notch depth is about $10 \mathrm{~dB}$. We can fabricate the PS-POFBGs in transmission with very sharp notches of $3 \mathrm{~dB}$ width, as shown in the inset of Fig. 2(a), depending on the total grating length (in this case $10 \mathrm{~mm}$ ). The refractive index modulation $\Delta n$ induced by the $\mathrm{KrF}$ laser can be deduced from the relation between the maximum reflect vity $R=\tanh ^{2}\left(\pi \Delta n L_{G} / \lambda_{B}\right)$, the Bragg wavelength $\lambda_{B}$ and grating length $L_{G}$. This gives an induced refractive index modulation of about $0.69 \times 10^{-4}$ for a reflec tivity of $-16.25 \mathrm{~dB}$. The fabricated PS-POFBG results in two Bragg structures with $L_{G} \approx 4.98 \mathrm{~mm}$ (each one), spatially separated by $L_{c} \approx 78.3 \mu \mathrm{m}$, and the estimated phase-shift from (2) is $\sim 4 \pi / 3$.

Fig. 2(b) compares the reflectio spectra of experimental and simulated ideal data, which shows a good agreement. The observed minor difference could be due to imperfections in the $\mathrm{POF}$ or deviations in the real grating length from the assumed 


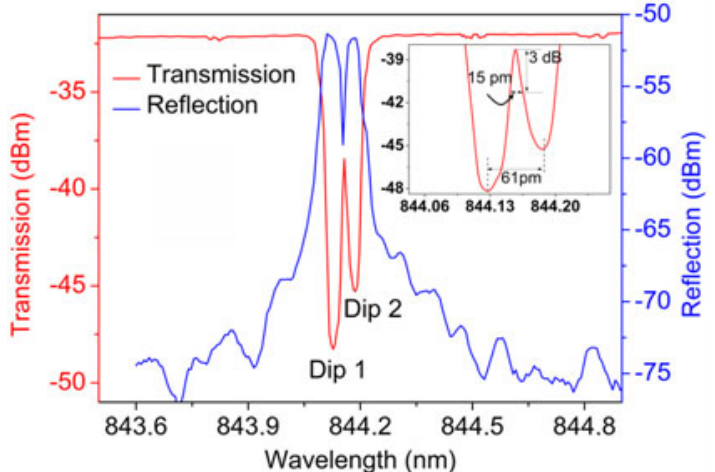

(a)

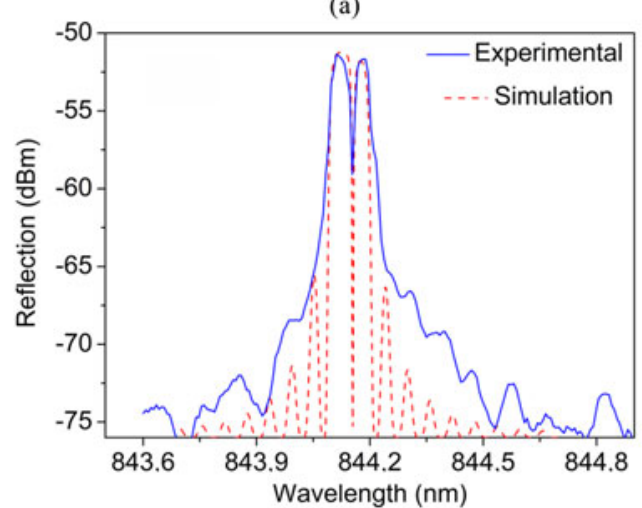

(b)

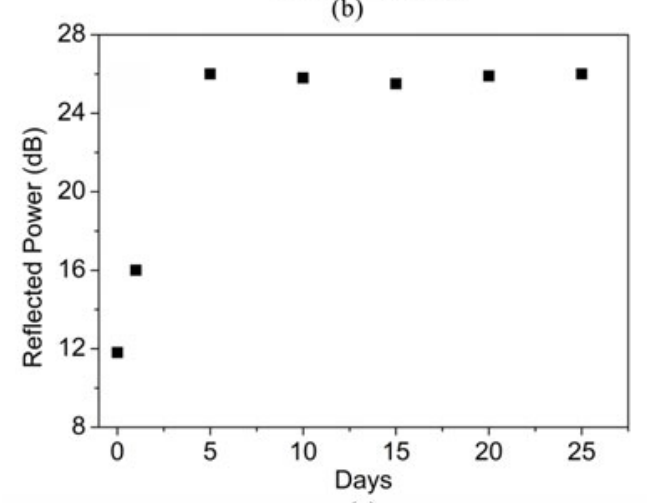

(c)

Fig. 2. (a) Transmission/reflectio spectra of inscribed PS-POFBG after a single UV pulse. (Inset: Bandwidth of the notch and transmission band.) (b) Simulation spectrum comparing with experimental one. (c) Stability process of the preannealed PS-POFBGs: measured between the noise level and the stronger peak of the reflectio bands.

phase mask length. This latter case can be explained by the fact that the FBG length inscribed not being the supposed real value, which depends of beam size exposing the phase mask (more than $10 \mathrm{~mm}$ in this case), the distance between the phase mask and the optical fibe, and the angle $\theta$ between the diffracted wave and the normal incidence [52]. In order to calculate $\theta$, the equation for diffraction gratings can be used, which is given by:

$$
n \sin (\theta)=n \sin \left(\theta_{1}\right) M \frac{\lambda}{\Lambda} .
$$

Considering $M=1$ and assuming a normal incidence $\left(\theta_{1}=\right.$ $0)$, we have:

$$
\theta=\arcsin \left(\frac{\lambda_{U V}}{\Lambda_{P M}}\right) .
$$

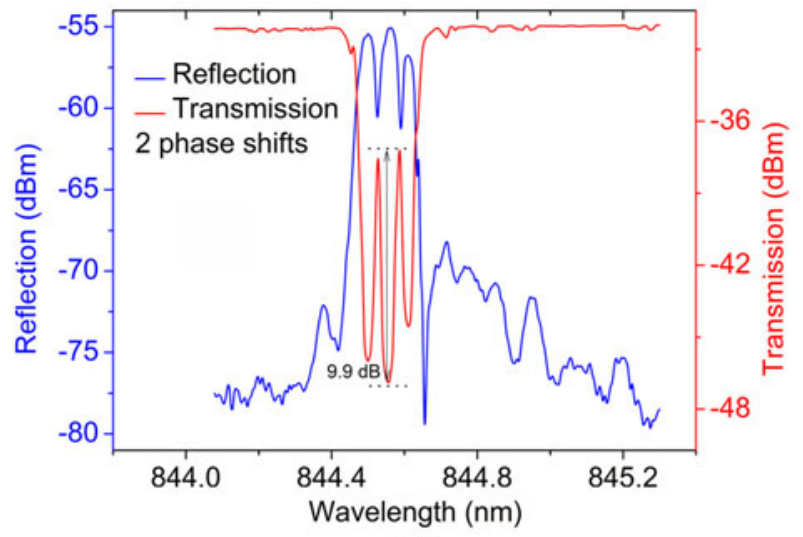

(a)

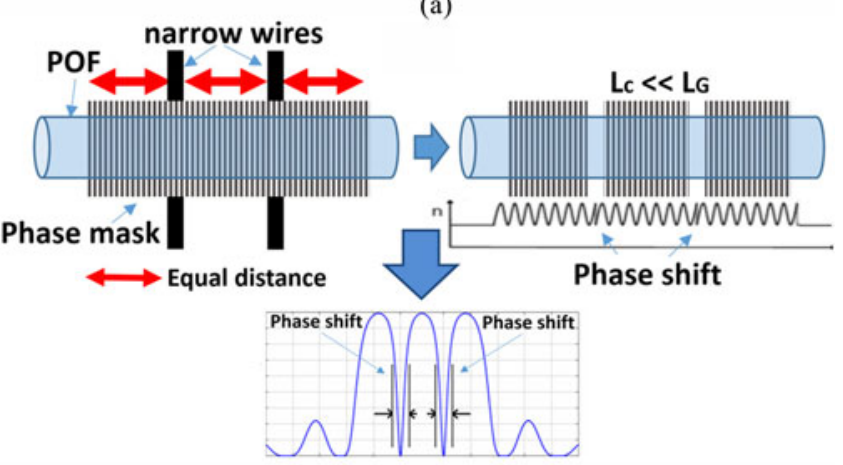

(b)

Fig. 3. (a) Transmission/reflectio spectra when two phase shifts are introduced in the mPOF. (b) A schematic configuratio of the multiple PS-POFBG fabricated by inscribing a Bragg structure with two narrow metal wires positioned in two different places equally spaced spatially.

Note that the angle $\theta$ depends on $\Lambda_{P M}$ and the wavelength of the UV laser. More details can be found in [52].

Comparing these PS-POFBG spectra with uniform POFBG spectra, the maximum slope is enhanced several orders of magnitude, which significantl enhances the sensitivity of the sensor [53], [54]. Although the dynamic range is lower in the PSPOFBG due to the narrow peak, it is not seen as a problem for ultrasonic detection or even accelerometer applications [27], since the strain applied is typically very small.

All our PS-POFBGs have been annealed at room temperature for 5 days to reach a stable regime as shown in [46]. An interesting stability of fabricated PS-POFBGs is observed after 5 days (see Fig. 2(c)). In order to check the long-term stability of this gratings type, some PS-POFBG samples were kept undisturbed for 15 weeks at room temperature and the reflect vity and wavelength variation are significantl small (around $2 \mathrm{~dB}$ and $0.6 \mathrm{~nm}$ maximum variation, respectively). Moreover, these kind of Bragg structures can be use as multiplexing elements in the same fibe and as the energy of each UV pulse can be well controlled, it is possible to achieve the optimal pulse energy to achieve the reflect vity desired.

Fig. 3(a) shows the reflectio and transmission spectra when several phase shifts are introduced in the FBG structure by using two narrow wires equally spaced spatially along the $10 \mathrm{~mm}$ phase mask, as illustrated in Fig. 3(b), still using only a single UV pulse. The two phase-shifts is seen to generate two 
well-define about $9.9 \mathrm{~dB}$ notches in the transmission spectrum with a channel spacing of about $58 \mathrm{pm}$. The maximum transmission loss is about $-14.7 \mathrm{~dB}$. Our technique to fabricate PS-POFBGs is thus able to generate multiple well-define phase-shifts and narrow notches in the transmission spectrum.

\section{Sensing CharacterizATION OF A PS-POFBG}

The pressure test of the PS-POFBG with two dips of $-16.25 \mathrm{~dB}$ and $-13.17 \mathrm{~dB}$ was carried out in a sealed pressure chamber, which is shown in Fig. 4(a). The fibe was prepared to collect data in transmission and it was fi ed and glued with slight pre-strain inside the plastic tubing section of the chamber (see Fig. 4(a)). In this way, any bending of the fibe was prevented as the strain ensured that the fibe is maintained straight inside the tube while the pressure was increased. Using a cylinder, compressed air was used to increase the pressure (monitored with a pressure gauge) within the chamber. The chamber end was sealed by means of a metal cap. Fig. 4(b) gives the changes of the transmission spectra for the PS-POFBG under different pressures in the range of 0 to $400 \mathrm{kPa}$ with a step of $100 \mathrm{kPa}$. 25 minutes' time interval was given between each pressure step, to guarantee the stability of the collected data.

From Fig. 4(c) we observe that there is a linear shift of the center wavelengths of the two dips with increasing/decreasing pressure, with a sensitivity of $0.46 \pm 0.03 \mathrm{pm} / \mathrm{kPa}$, which is 2 times more sensitive than a uniform POFBG [54]. As Young's modulus of the polymer fibe $(\sim 2.9 \mathrm{GPa})$ is much lower than that of silica fibe $(\sim 70 \mathrm{GPa})$, the pressure sensitivity of sensors based on POF could be comparatively higher than that of silica fibe [55]. It should be noted that, in the case of a silica FBG, the hydrostatic pressure induced grating period change (strain effect) dominates the change in refractive index and as a result a negative sensitivity is observed [55], [56]. While for a POFBG, the dominant effect is the refractive index change than the grating period change and as a result the sensitivity becomes positive as shown in Fig. 4(c) for the case of PS-POFBGs. Moreover, the whole transmission spectrum shifts with the pressure variations and no significan distortion of its shape is observed, which is dissimilar from the PS-FBG achieved for example in a side-hole silica fibe [57]. The transmission losses of the 1st and 2nd dips have obvious changes under pressure variation (see Fig. 4(b)), but the transmission notch depth remains relatively stable. The intensity losses under pressure can be caused by many reasons where the pressure can influenc the physical dimensions of fibe and its optical properties [58]. Fig. 4(c) shows the transmission notch depth variation under different pressures and the maximum loss difference is just around $0.4 \mathrm{~dB}$. Furthermore, the spectral separation of the two dips with increasing pressure was analyzed. Fig. 4(d) shows that there is no significan change in the spectral separation when the pressure is increased.

With the increase of the pressure inside the chamber a temperature variation will be registered due to the air pumping. As it is known that the POFBG is sensitive to temperature a temperature sensor was included in the setup, as seen in Fig. 4(a), in order to compensate the temperature induced effect on the POFBG. For a pressure change of $0-400 \mathrm{kPa}$, a $2{ }^{\circ} \mathrm{C}$ variation

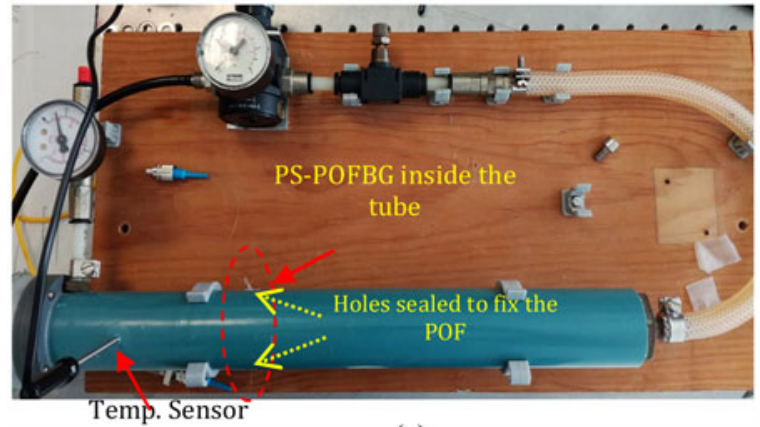

(a)

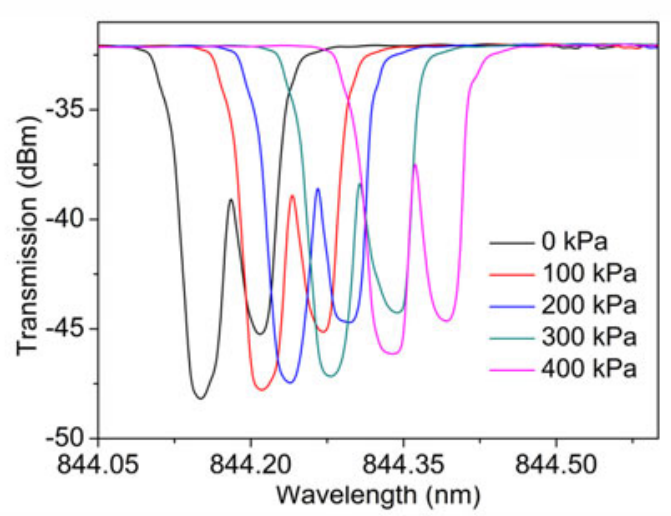

(b)

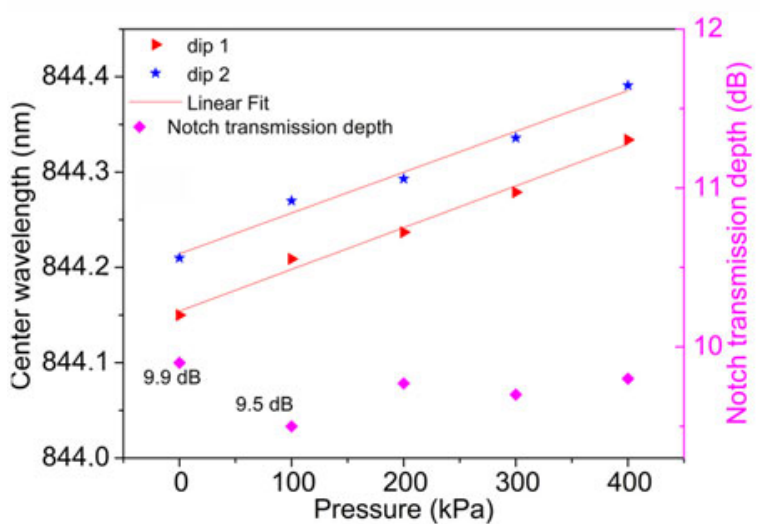

(c)

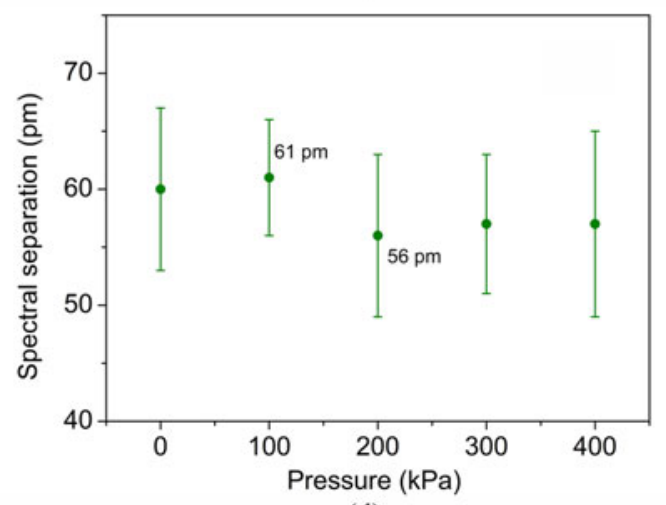

(d)

Fig. 4. (a) Hydrostatic pressure apparatus. (b) Transmission spectra behavior under different pressures from 0 to $400 \mathrm{kPa}$. (c) Bragg wavelength shifts and transmission notch depth behavior obtained from the inscribed PS-POFBG under different pressures. (d) Separation of the spectral notches with increasing pressure. 
was registered inside the chamber and this behavior could cause the transmission losses of the dip 1 and 2 observed in Fig. 4(b). As the temperature inside the chamber is not constant and a variation around $2{ }^{\circ} \mathrm{C}$ was measured during the experiment, this temperature variation can induce stress on POF and consequently influenc the transmission losses.

A thermal characterization of the device in terms of the properties of the notches was performed using a climate chamber. The temperature was raised from $22^{\circ} \mathrm{C}$ to $52^{\circ} \mathrm{C}$ in $5{ }^{\circ} \mathrm{C}$ steps. A 30 minutes' stabilization time was given in each step to ensure thermal equilibrium. The full transmission profile are shown in Fig. 5(a). In Fig. 5(b) we show the separation of the notches versus temperature and observe a low sensitivity to temperature. Though the spectral separation of the notches is temperature insensitive, their spectral positions are very sensitive to temperature, as shown in Fig. 5(a). To evaluate the temperature sensing ability of the PS-POFBG, the temperature sensitivity of the center wavelength of both dips was measured. From Fig. 5(c). A change of $-1.71 \mathrm{~nm}$ in Bragg wavelength over the $30^{\circ} \mathrm{C}$ temperature variation was observed. The temperature sensitivity was found to be $-57 \pm 4 \mathrm{pm} /{ }^{\circ} \mathrm{C}$ using a linear best fit which is significantl stronger than the $\sim 10.3 \mathrm{pm} /{ }^{\circ} \mathrm{C}$ of silica PS-FBG [59]. Also, this achieved temperature sensitivity is similar to the values already reported for uniform FBGs in the same polymer fibe $\left(-59 \mathrm{pm} /{ }^{\circ} \mathrm{C}\right)[60]$. From Fig. 5(a), the transmission losses of both dips is seen to decrease for higher temperatures. The loss at the notch wavelengths is shown in Fig. 5(d), from which a nonlinear dependency of the loss on temperature is found, which results in a decrease in the loss of about $3 \mathrm{~dB}$ from 22 to $52{ }^{\circ} \mathrm{C}$. These values were found from Fig. 5(a) and this nonlinear dependency can be influence by temperature changes after a considerable temperature value [61]. There is a decreasing of the reflect vity when temperature change considerably, which is chiefl due to photo-polymerization. At room temperature, the light scattering is very small and is approximately zero at about $30{ }^{\circ} \mathrm{C}$. When the temperature increases, the refractive index of the polymer changes more steeply and hence, the difference between the indices increases gradually with temperature. In turn, this produces an increasing of the scattering up to the transition temperature, where the sample becomes completely opaque.

Additionally, a strain characterization was performed. The strain test of PS-POFBG was implemented by fixin the fibe between a fi ed and a movable (manual translating stage) platforms, with the minimum distance between the fi ed points of $483 \mathrm{~mm}$. Also, we should mention that each time the POF was strained, a sufficien time $(\sim 3 \mathrm{~min})$ was spent waiting for the Bragg wavelength to stop shifting due to hysteresis or creep effects, minimizing as much as possible the readout error. On the other hand, using annealed PS-POFBGs, there was a significan improvement of the peak intensity stability, no peak splitting at high loading strain, and strain can be applied to the annealed POF gratings with small amount of hysteresis [26], [62]. From the experimental data shown in Fig. 6(a) we can see that the strain response of both dips of the PS-POFBG shows good linearity, the estimated strain sensitivity was $0.76 \pm 0.01 \mathrm{pm} / \mu \varepsilon$, which is slightly larger than the $0.7 \mathrm{pm} / \mu \varepsilon$ of the silica PS-FBG reported in [59]. A reversible process can be observed when

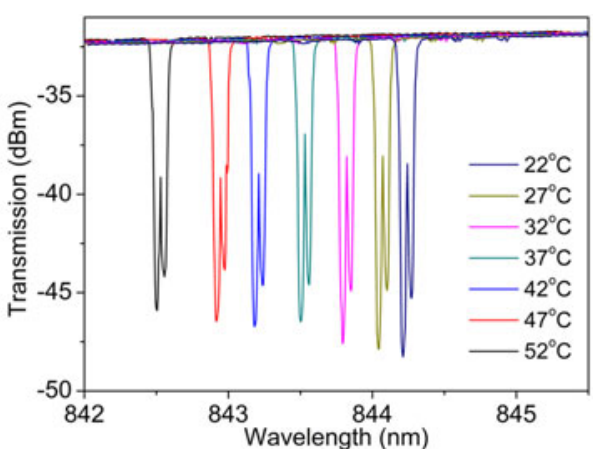

(a)

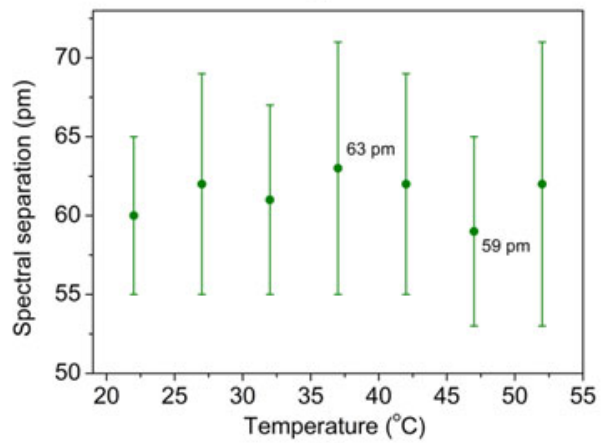

(b)

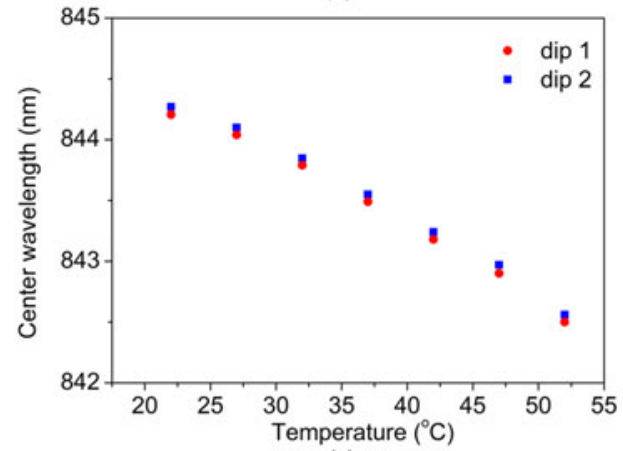

(c)

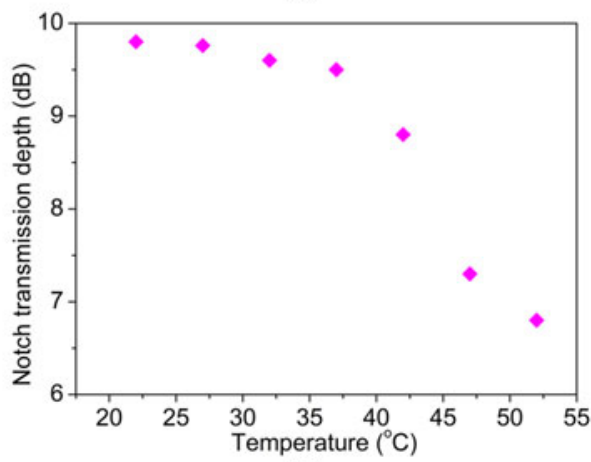

(d)

Fig. 5. (a) Transmission spectrum of a PS-POFBG at different temperatures. (b) Separation of the spectral notches with increasing temperature. (c) Change of the center wavelengths of both dips and (d) transmission notch depth variation with increasing temperature.

the strain decreases showing a very small amount of hysteresis, in which the annealing process employed to the POFBG helps for this fact [26], [51]. Fig. 6(b) depicts the spectral separation between the two dips with increasing strain and it is insensitive to strain. 


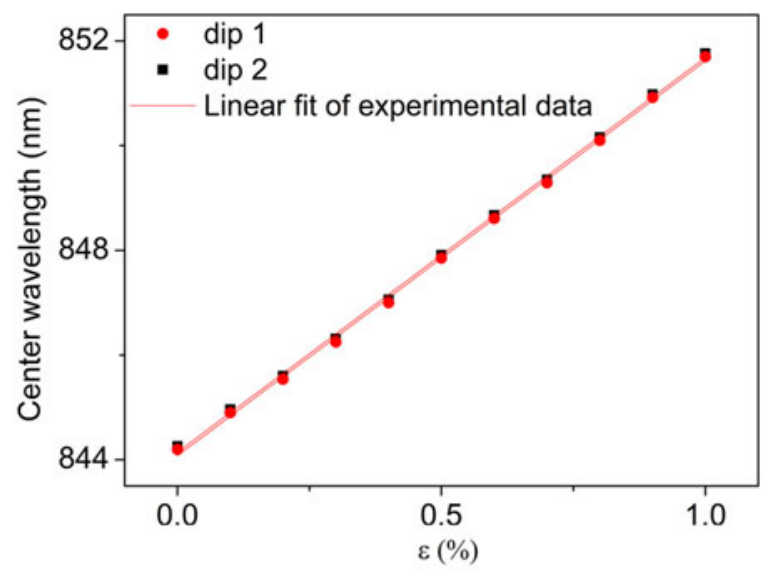

(a)

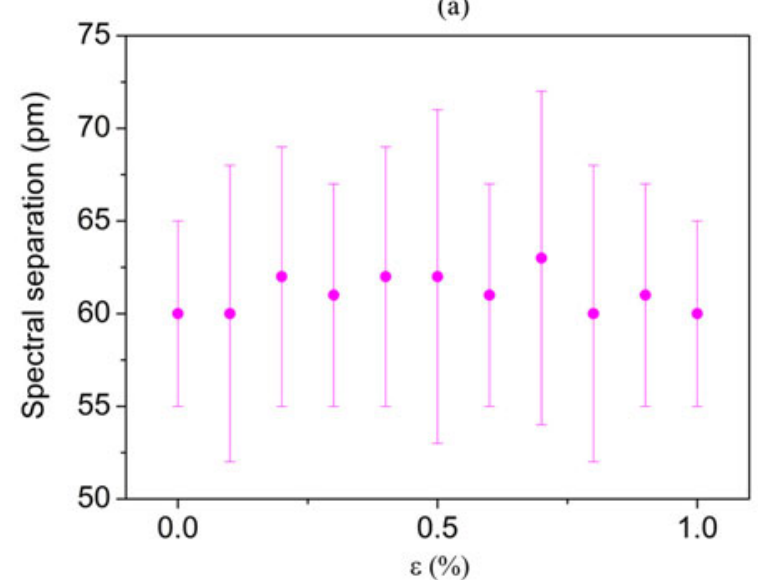

(b)

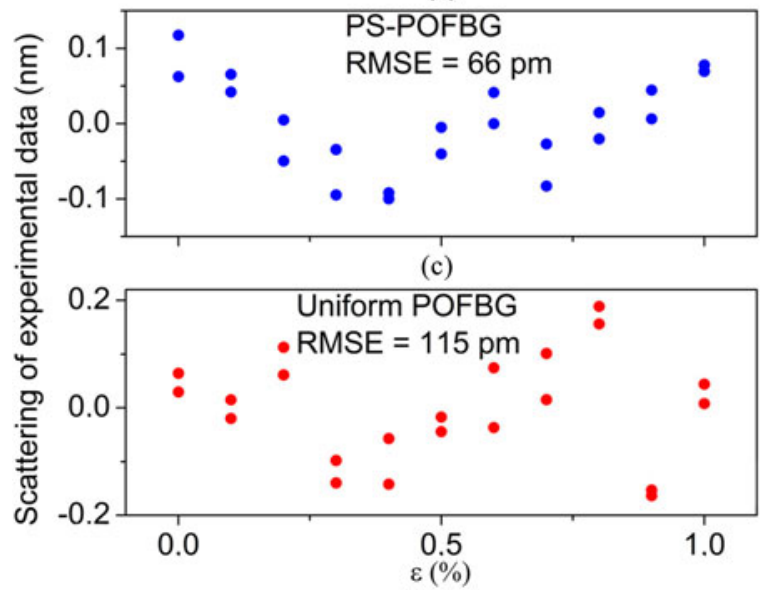

(d)

Fig. 6. (a) Changes of the central wavelengths (b) and spectral separation between the two dips with increasing strain. Scattering of the measurement points around the trend line from which we calculated the standard deviation error amounting to (c) $66 \mathrm{pm}$ (PS-POFBG) and (d) $115 \mathrm{pm}$ (uniform POFBG).

In Fig. 6(c) we present a scattering of the measurement points around the fi of each peak for the elongation series for both peaks, from which we calculated the standard deviation amounting to $66 \mathrm{pm}$. We repeated the same procedure using a single Bragg grating where a standard deviation of $115 \mathrm{pm}$ was computed for the increasing strain as shown in Fig. 6(d). The obtained results confir an advantage of the PS-POFBGs over the single Bragg grating, since for the PS-POFBG the standard

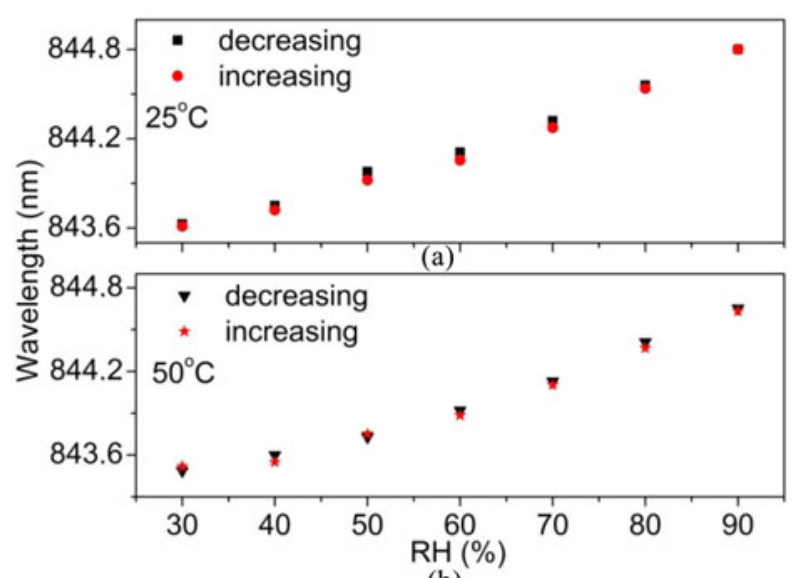

(b)

Fig. 7. Bragg wavelength change versus increasing/decreasing in relative humidity at (a) $25^{\circ} \mathrm{C}$ and (b) $50{ }^{\circ} \mathrm{C}$ using preannealed PS-POFBGs in hot water $(100 \% \mathrm{RH})$ at $60^{\circ} \mathrm{C}$.

deviation from the linear trend is almost reduced by factor of 2. It is expected that this number can be further increased by improving precision in setting the fibe elongations during the strain measurements.

In the last characterization step, the humidity response of the PS-POFBG has been measured at two distinct temperatures: $25{ }^{\circ} \mathrm{C}$ and $50{ }^{\circ} \mathrm{C}$, in the interval of $30-90 \%$ relative humidity $(\mathrm{RH})$, where the environmental chamber had greatest stability with a precision less than $0.4{ }^{\circ} \mathrm{C}$ and $1 \% \mathrm{RH}$. For each temperature level, the humidity values were collected by increasing the RH starting from $30 \%$ up to $90 \%$ in a $10 \%$ step increase, and then decreasing it from $90 \%$ to $30 \%$. In each step, the chamber maintained the environmental conditions stable for $60 \mathrm{~min}$. Note that the fibe pieces were pre-annealed with the same procedure used in [50], where the fibe was placed for 15 minutes in a container fille with water (giving us $100 \% \mathrm{RH}$ ) that was heated at $60 \pm 1{ }^{\circ} \mathrm{C}$. For this PS-POFBG the sensitivities returned by linear regression at $25^{\circ} \mathrm{C}$ and $50^{\circ} \mathrm{C}$ are $19.8 \pm 2.5$, $19.6 \pm 2.4 \mathrm{pm} / \% \mathrm{RH}$ for increasing humidity and $19.6 \pm 2.1$, $18.9 \pm 2.4 \mathrm{pm} / \% \mathrm{RH}$ for decreasing humidity, respectively. The $\lambda_{B}$ changes with the increasing/decreasing $\mathrm{RH}$ at the two temperatures is plotted in Fig. 7. This is considerably less than the sensitivity recently achieved in [25], [63], however it can be justifie by the dopant of the fibe. The PS-POFBG annealed to $100 \%$ RH not only had the largest sensitivity as discussed in [25], but also the lowest level of hysteresis, i.e., the smallest difference in sensitivity to humidity between the forward and reverse experiments. In order to compare this latter result, we pre-annealed some fibe pieces during 6 hours setting the climate chamber at $60{ }^{\circ} \mathrm{C}$ and $50 \% \mathrm{RH}$, and then inscribed PSPOFBGs in these fibers Then, we repeated the same procedure for the humidity characterization step. From Table I, it is important to notice that the hysteresis is considerably increased for the PS-POFBGs that have been annealed at lower levels of humidity. In addition, these PS-POFBGs annealed at low humidity also display a non-stable humidity response with hysteresis that increases with temperature and a sensitivity that decreases with temperature. 
TABLE I

HUMIDITy RESPONSE AND HYSTERESIS FOR DIFFERENT ANNEALED PS-POFBGS

\begin{tabular}{ccc}
\hline & $\begin{array}{c}\text { Humidity sensitivity } \\
(\mathbf{p m} / \% \mathbf{R H})\end{array}$ & $\begin{array}{c}\text { Hysteresis } \\
(\mathbf{p m})\end{array}$ \\
\hline \% RH & Increase/decrease & \\
\hline $\mathbf{5 0}$ & & \\
At $25^{\circ} \mathrm{C}$ & $15.70 / 16.15$ & 115 \\
At $50^{\circ} \mathrm{C}$ & $14.58 / 15.05$ & 195 \\
$\mathbf{1 0 0}$ & & \\
At $25^{\circ} \mathrm{C}$ & $19.85 / 19.60$ & 47 \\
At $50^{\circ} \mathrm{C}$ & $19.61 / 18.90$ & 64
\end{tabular}

\section{CONCLUSION}

In this work, we demonstrate and report for the firs time, the fast inscription of high-quality PS-FBGs in a doped PMMA $\mathrm{mPOF}$, with only one KrF laser pulse. The gratings were successful produced through the phase mask technique, using $248 \mathrm{~nm}$ UV light. The PS-POFBGs were created at $850 \mathrm{~nm}$ and the produced Bragg grating structure rejects $16.3 \mathrm{~dB}$ transmitted power (from the stronger dip), which is well suited for photonics applications. Moreover, this work presents a new way to achieve high-quality mPOF devices for highly sensitive ultrasonic systems, which require high-precision measurements. Also, the ability to inscribe multiple phase-shifts in a POFBG structure was successfully demonstrated. The spectral dependence of the PS-POFBG under pressure (0-400 $\mathrm{kPa}$ range) and strain was found to be approximately linear with a sensitivity of $0.46 \pm 0.03 \mathrm{pm} / \mathrm{kPa}$ and $0.76 \pm 0.01 \mathrm{pm} / \mu \varepsilon$, respectively. The PS-POFBG was characterized for humidity and temperature and sensitivities reaching $19.9 \pm 2.5 \mathrm{pm} / \% \mathrm{RH}$ and $-57 \pm 1 \mathrm{pm} /{ }^{\circ} \mathrm{C}$, respectively for relative humidities from $30 \%$ to $90 \%$ and temperatures between 22 and $52{ }^{\circ} \mathrm{C}$.

\section{REFERENCES}

[1] M. H. Asghari and J. Azaña, "All-optical Hilbert transformer based on a single phase-shifted fibe Bragg grating: Design and analysis," Opt. Lett., vol. 34, pp. 334-336, 2009.

[2] M. Li and J. P. Yao, "Experimental demonstration of a wideband photonic temporal Hilbert transformer based on a single fibe Bragg grating," IEEE Photon. Technol. Lett., vol. 22, no. 21, pp. 1559-1561, Nov. 2010.

[3] L. Gao, J. Zhang, X. Chen, and J. Yao, "Microwave photonic filte with two independently tunable passbands using a phase modulator and an equivalent Phase-Shifted fibe bragg grating," IEEE Trans. Microw. Theory Techn., vol. 62, no. 2, pp. 380-387, Feb. 2014.

[4] R. C. Alferness, C. H. Joyner, M. D. Divino, M. J. R. Martyak, and L. L. Buhl, "Narrowband grating resonator filter in InGaAsP/InP waveguides," Appl. Phys. Lett., vol. 49, 1986, Art. no. 125.

[5] J. Canning and M. G. Sceats, "Pi-phase shifted periodic distributed structures in optical fibre by UV post-processing," Electron. Lett., vol. 30, no. 16 , pp. 1344-1345, 1994.

[6] R. Kashyap, P. F. McKee, and D. Armes, "UV written reflectio grating structures in photosensitive optical fibre using phase-shifted masks," Electron. Lett., vol. 30, no. 23, pp. 1977-1978, Nov. 1994.

[7] C. A. F. Marques, V. Oliveira, H. J. Kalinowski, and R. N. Nogueira, "Production of optical notch filter with fin parameter control using regenerated fibe Bragg gratings," Opt. Lett., vol. 37, no. 10, pp. 1697-1699, 2012.

[8] D. Uttamchandani and A. Othonos, "Phase shifted Bragg gratings formed in optical fibre by post-fabrication thermal processing," Opt. Commun., vol. 127, pp. 200-204, 1996.
[9] A. Rosenthal et al., "Sensitive interferometric detection of ultrasound for minimally invasive clinical imaging applications," Laser Photon. Rev., vol. 8, pp. 450-457, 2014.

[10] G. Rousseau, A. Blouin, and J.-P. Monchalin, "Non-contact photoacoustic tomography and ultrasonography for tissue imaging," Biomed. Opt. Express, vol. 3, pp. 16-25, 2012.

[11] G. Wild and S. Hinckley, "Acousto-ultrasonic optical fibe sensors: Overview and state-of-the-art," IEEE Sens. J., vol. 8, no. 7, pp. 1184-1193, Jul. 2008.

[12] A. Minardo, A. Cusano, R. Bernini, L. Zeni, and M. Giordano, "Response of fibe Bragg gratings to longitudinal ultrasonic waves," IEEE Trans. Ultrason., Ferroelectr., Freq. Control, vol. 52, no. 2, pp. 304-312, Feb. 2005.

[13] A. Rosenthal, R. Razansky, and V. Ntziachristos, "High-sensitivity compact ultrasonic detector based on a pi-phase shifted fibe Bragg grating," Opt. Lett., vol. 36, pp. 1833-1835, 2011.

[14] Q. Wu and Y. Okabe, "High-sensitivity ultrasonic phase-shifted fibe Bragg grating balanced sensing system," Opt. Express, vol. 20, pp. 28353-28362, 2012

[15] J. J. Guo and C. X. Yang, "Highly stabilized phase-shifted fibe Bragg grating sensing system for ultrasonic detection," IEEE Photon. Technol. Lett., vol. 27, no. 8, pp. 848-851, Apr. 15, 2015.

[16] I. P. Johnson et al.," "Optical fibr Bragg grating recorded in TOPAS cyclic olefi copolymer," Electron. Lett., vol. 47, no. 4, pp. 271-272, Feb. 17, 2011.

[17] I. L. Bundalo, K. Nielsen, and O. Bang, "Angle dependent Fiber Bragg grating inscription in microstructured polymer optical fibers" Opt. Express, vol. 23, p. 3699-3707, 2015.

[18] X. Hu et al., "Polarization effects in polymer FBGs: Study and use for transverse force sensing," Opt. Express, vol. 23, pp. 4581-4590, 2015.

[19] D. J. Webb, "Fibre Bragg grating sensors in polymer optical fibres" Meas. Sci. Technol., vol. 26, 2015, Art. no. 092004.

[20] X. Hu, C. F. J. Pun, H. Y. Tam, P. Mégret, and C. Caucheteur, "Tilted Bragg gratings in step-index polymer optical fiber" Opt. Lett., vol. 39, pp. $6835-6838,2014$.

[21] C. A. F. Marques, P. Antunes, P. Mergo, D. J. Webb, and P. André, “Chirped Bragg gratings in PMMA step-index polymer optical fiber" IEEE Photon. Technol. Lett., vol. 29, no. 6, pp. 500-503, Mar. 2017.

[22] G. Statkiewicz-Barabach, P. Mergo, and W. Urbanczyk, "Bragg gratingbased Fabry-Perot interferometer fabricated in a polymer fibe for sensing with improved resolution," J. Opt., vol. 19, 2016, Art. no. 015609.

[23] W. Yuan, A. Stefani, and O. Bang, "Tunable polymer fibe Bragg grating (FBG) inscription: fabrication of dual-FBG temperature compensated polymer optical fibe strain sensors," IEEE Photon. Technol. Lett., vol. 24, no. 5, p. 401-403, Mar. 2012.

[24] C. A. F. Marques, L. Bilro, L. Kahn, R. A. Oliveira, D. J. Webb, and R. N. Nogueira, "Acousto-optic effect in microstructured polymer fibe Bragg gratings: Simulation and experimental overview," J. Lightw. Technol., vol. 31, no. 10, pp. 1551-1558, May 2013.

[25] G. Woyessa, K. Nielsen, A. Stefani, C. Markos, and O. Bang, “Temperature insensitive hysteresis free highly sensitive polymer optical fibr Bragg grating humidity sensor," Opt. Express, vol. 24, pp. 1206-1213, 2016.

[26] A. Stefani, S. Andresen, W. Yuan, N. Herholdt-Rasmussen, and O. Bang, "High sensitivity polymer optical Fiber-Bragg-Grating-Based accelerometer," IEEE Photon. Technol. Lett., vol. 24, no. 9, pp. 763-765, May 2012.

[27] C. A. F. Marques, G. D. Peng, and D. J. Webb, "Highly sensitive liquid level monitoring system utilizing polymer fibe Bragg gratings," Opt. Express, vol. 23, pp. 6058-6072, 2015.

[28] C. A. F. Marques, A. Pospori, D. Sáez-Rodríguez, K. Nielsen, O. Bang, and D. J. Webb, "Aviation fuel gauging sensor utilizing multiple diaphragm sensors incorporating polymer optical fibe Bragg gratings," IEEE. Sens. $J$., vol. 16, no. 15 , pp. 6122-6129, Aug. 2016.

[29] G. Emiliyanov, P. E. Høiby, L. H. Pedersen, and O. Bang, "Selective serial multi-antibody biosensing with TOPAS microstructured polymer optical fibers" Sensors, vol. 13, pp. 3242-3251, 2013.

[30] G. Emiliyanov et al., "Localized biosensing with Topas microstructured polymer optical fiber" Opt. Lett., vol. 32, pp. 460-462, 2007.

[31] J. B. Jensen, P. E. Hoiby, G. Emilianov, O. Bang, L. H. Pedersen, and A. Bjarklev, "Selective detection of antibodies in microstructured polymer optical fibers" Opt. Express, vol. 13, pp. 5883-5889, 2005.

[32] H. Lamela, D. Gallego, and A. Oraevsky, "Optoacoustic Imaging using fibe -optic interferometric sensors," Opt. Lett., vol. 34, pp. 3695-3697, 2009. 
[33] D. Gallego and H. Lamela, "High-sensitivity ultrasound interferometric single-mode polymer optical fibe sensors for biomedical applications," Opt. Lett., vol. 34, p. 1807-1809, 2009.

[34] D. Gallego, D. Saez Rodriguez, D. Webb, O. Bang, and H. Lamela, "Interferometric microstructured polymer optical fibe ultrasound sensor for optoacoustic endoscopic imaging in biomedical applications," Proc. SPIE, vol. 9157, 2014, Art. no. 91574X.

[35] C. Broadway et al., "Fabry-Perot micro-structured polymer optical fibr sensors for opto-acoustic endoscopy," Proc. SPIE, vol. 9531, 2015, Art. no. 953116.

[36] C. Broadway et al., "A compact polymer optical fibr ultrasound detector," Proc. SPIE, vol. 9708, 2016, Art. no. 970813.

[37] D. Gallego and H. Lamela, "Microstructured polymer optical fibe sensors for optoacoustic endoscopy," Proc. SPIE, vol. 10064, 2017, Art no. 1006412.

[38] S. F. Zhou, L. Reekie, Y. T. Chow, H. P. Chan, and K.i M. Luk, "Phaseshifted fibe Bragg gratings for terahertz range," IEEE Photon. Technol. Lett., vol. 24, no. 20, pp. 1875-1877, Oct. 2012.

[39] H. Dobb et al., "Grating based devices in polymer optical fibre" Proc. SPIE, vol. 6189, 2006, Art. no. 618901

[40] F. Ghiringhelli, C. Alegria, and M. N. Zervas, "Effect of phase shift perturbations and complex local time delay in fibe Bragg gratings," in Proc. Bragg Gratings, Photosensitivity, Poling Glass Waveguides, 2001, Paper BWA3.

[41] J. Y. Lee, H.-W. Lee, and J. W. Hahn, "Complex traversal time for optical pulse transmission in a Fabry-Perot cavity," J. Opt. Soc. Amer. B, vol. 17, pp. 401-406, 2000.

[42] Y. Liu, S. B, Lee, and S. S. Choi, "Phase shifted fibe Bragg gratings transmission filter based on the Fabry-Perot effect," J. Opt. Soc. Korea, vol. 2, pp. 30-33, 1998.

[43] G. P. Agrawal and S. Radic, "Phase-shifted fibe Bragg gratings and their application for wavelength demultiplexing," IEEE Photon. Technol. Lett., vol. 6, no. 8, pp. 995-997, Aug. 1994.

[44] H. Franke, "Optical recording of refractive-index patterns in doped poly(methyl methacrylate) films" Appl. Opt., vol. 23, pp. 2729-2733, 1984.

[45] D. Sáez-Rodríguez, K. Nielsen, H. K. Rasmussen, O. Bang, and D. J. Webb, "Highly photosensitive polymethyl methacrylate microstructured polymer optical fibe with doped core," Opt. Lett., vol. 38, pp. 3769 $3772,2013$.

[46] A. Pospori, C. A. F. Marques, O. Bang, D. J. Webb, and P. André "Polymer optical fibe Bragg grating inscription with a single UV laser pulse," Opt. Express, vol. 25, pp. 9028-9038, 2017

[47] Y. Luo, Q. Zhang, H. Liu, and G. D. Peng, "Gratings fabrication in benzi dimethyl ketal doped photosensitive polymer optical fiber using $355 \mathrm{~nm}$ nanosecond pulsed laser," Opt. Lett., vol. 35, pp. 751-753, 2010.

[48] I.-L. Bundalo, K. Nielsen, C. Markos, and O. Bang, "Bragg grating writing in PMMA microstructured polymer optical fiber in less than 7 minutes," Opt. Express, vol. 22, pp. 5270-5276, 2014

[49] A. Stefani, K. Nielsen, H. K. Rasmussen, and O. Bang, "Cleaving of TOPAS and PMMA microstructured polymer optical fibers Coreshift and statistical quality optimization," Opt. Commun., vol. 285, pp. 1825-1833, 2012.
[50] A. Abang, D. Sáez-Rodríguez, K. Nielsen, O. Bang, and D. J. Webb, “Connectorisation of fibr Bragg grating sensors recorded in microstructured polymer optical fibre, Proc. SPIE, vol. 8794, 2013, Art. no. 87943Q.

[51] A. Pospori, C. A. F. Marques, D. Sáez-Rodríguez, K. Nielsen, O. Bang, and D. J. Webb, "Thermal and chemical treatment of polymer optical fibe Bragg grating sensors for enhanced mechanical sensitivity," Opt. Fiber Technol., vol. 36, pp. 68-74, 2017.

[52] C. A. F. Marques, "Fiber-optic components for optical communications and sensing," Ph.D. dissertation, Univ. Aveiro, Aveiro, Portugal, 2013. [Online]. Available: https://ria.ua.pt/handle/10773/12218

[53] A. Rosenthal, D. Razansky, and V. Ntziachristos, "High-sensitivity compact ultrasonic detector based on a pi-phase-shifted fibe Bragg grating," Opt. Lett., vol. 36, pp. 1833-1835, 2011.

[54] Q.-Wu and Y. Okabe, "High-sensitivity ultrasonic phase-shifted fibe Bragg grating balanced sensing system," Opt. Express, vol. 20, pp. 28353-28362, 2012.

[55] K. Bhowmik et al., "Experimental study and analysis of hydrostatic pressure sensitivity of polymer fibr Bragg gratings," J. Lightw. Technol., vol. 33, no. 12, pp. 2456-2462, Jun. 2015.

[56] I. P. Johnson, D. J. Webb, and K. Kalli, "Hydrostatic pressure sensing using a polymer optical fibr Bragg gratings," Proc. SPIE, vol. 8351, 2012, Art. no. 835106

[57] Q. Zhang, N. Liu, T. Fink, H. Li, W. Peng, and M. Han, "Fiber-optic pressure sensor based on $\pi$-phase-shifted fibe Bragg grating on sidehole f ber," IEEE Photon. Technol. Lett., vol. 24, no. 17, pp. 1519-1522, Sep. 2012.

[58] M. G. Laka and A. A. Dzenis, "Effect of hydrostatic pressure on the tensile strength of polymer materials," Polymer Mech., vol. 3, pp. 685-687, 1967.

[59] S. F. O. Silva, L. A. Ferreira, F. M. Araújo, J. L. Santos, and O. Frazão, "Fiber Bragg grating structures with fused tapers," Fiber Integr. Opt., vol. 30, pp. 9-28, 2011

[60] C. Marques, A. Pospori, D. Sáez-Rodríguez, K. Nielsen, O. Bang, and D. J. Webb, "Fiber optic liquid level monitoring system using microstructured polymer fibe Bragg grating array sensors: performance analysis," Proc. SPIE, vol. 9634, 2015, Art. no. 96345V.

[61] U. Bernini, P. Russo, M. Malinconico, E. Martucelli, M. G. Volpeau, and P. Mormile, "Temperature dependent optical properties of a synthesis blend of poly (methyl methacrylate) and vinyl rubber," J. Mater. Sci., vol. 28, pp. 6399-6402, 1993.

[62] W. Yuan et al., "Improved thermal and strain performance of annealed polymer optical fibe Bragg gratings," Opt. Commun., vol. 284, pp. 176-182, 2011

[63] G. Woyessa et al., "Zeonex-PMMA microstructured polymer optical FBGs for simultaneous humidity and temperature sensing," Opt. Lett., vol. 42, pp. 1161-1164, 2017. 